equal force to hospitals, auditoriums, stores, factories and all other types of buildings.

In conclusion be it said that given authoritative standards, the employment of capable consulting engineers, a proper appropriation for the installation of the heating and ventilating system, a reasonable freedom to the engineer in the working out and in the application of his design, and skillful operation, and the engineer's problems in mechanical ventilation will have been overcome.

Without the consummation of these ends the splendid efforts now being made to solve the chemical, physical, physiological, psychological, efficiency and comfort problems of ventilation will have been wasted.

15 West 38Th StreET, New York City

\section{INVESTIGATION OF SCHOOL AIR IN NEW YORK CITY}

\author{
By Charles BaskerviLLe
}

The Public School System of Greater New York has to do with over 700,000 children requiring the services of about 18,000 teachers with an annual expenditure of approximately $\$ 40,000,000$. The Board of Estimate and Apportionment approves all appropriations, which to be available must subsequently be passed upon by the Board of Aldermen. A special Committee on School Inquiry was appointed by the Board of Estimate and Apportionment to look into the problem of efficiency of the entire school system, involving the child, its instruction, and physical environment.

The Committee desiring to utilize the equipment and services of some of the staff of the College of the City invited me to undertake the study of the air of the New York City Schools. The invitation was accepted after I had succeeded in securing the cooperation of my colleague, Professor C.-E. A. Winslow, who subsequently was selected as chairman of the New York State Commission on Ventilation.

Our work constituted a part of the investigation assigned to Mr. Chas. G. Armstrong, the engineer to the School Inquiry Committee.

A preliminary investigation was made during the spring of I9 2 after the ventilating plants in those schools having them had been shut down. For this work $\$ 750$ was allowed. The work was continued, on our recommendation, in the fall of Igra and winter of 1913, when the various ventilating systems were in operation, with a further expenditure of about $\$ 7,500$. Neither Professor Winslow nor I accepted compensation for our services in connection with the investigation. The money was spent for the services of assistants and special apparatus. Space admits only a very brief summary of our work, the full report of which is now in press by order of the School Inquiry Committee referred to.

Our problem was to determine the quality of New York air and if possible express an opinion upon the efficiency of the several systems of ventilation in operation in the schools, which might serve as a guide in making recommendations looking toward the re-construction of some of the school buildings, or, better operation of the systems already installed, and to advise as to future construction. We were able to meet these demands in part only, some reasons for which will be clear in what Professor Winslow will say in the last paper to be presented this evening. Other reasons are presented herewith.

The systems studied were ( $I$ ), window system (designated the "open window" method by the lay press); (2), the natural system, where ducts were provided, but no mechanical means for insuring a flow of air in a desired direction or regulating the speed of the flow; (3), mechanical ventilation by means of fans with heating coils in the main duct; and (4), the last mentioned provided further with a washer, which also acted as a humidifier. In some, in fact practically all, schools investigated, where mechanical ventilation was the method used, the air was taken in at or near the street level and not filtered, except in so far as in special cases, we may regard passing through a spray of water as filtration, which it undoubtedly is. In this connection, however, it is important to note that after it became known that we had begun the preliminary investigation-or perhaps it was coincident with our beginning-the Board of Education appointed a committee headed by Hon. John Martin, to study the matter of ventilation in the schools, which committee made a very common sense report, whereupon the Superintendent of Schools, Dr. Maxwell, not only authorized, but ordered, the teachers in the schools to open the windows in whatever school they might be, at any time they deemed it desirable, it mattered not what system was in operation or how efficient it might be operating, thus placing another duty upon the teacher already overloaded with responsibility. Our field squads encountered these and many other conditions in their work. Acting under orders they made their observations of existing conditions as they found them. Of necessity, the comparative value of our investigation from a refined point of view was materially lessened. However, what we did learn proved of no little value as will become apparent to one who studies the report.

Two fundamental facts presented themselves to us at the outset; first, the quality of the air of the city itself, and second, the quality of the ait in different localities of the city.

When it is considered that the children are in school $5 / 24$ of a day for 5 days in a week for 8 months, that is to say, about 1000 hours of the total 8760 hours of the year, approximately $3 / 24$ of their existence, while the remaining $21 / 24$ of their time is spent in the streets, where the air is superior in certain ways and far inferior in others, and in their homes, where different features are better, but others worse, it becomes a matter of no small moment to recommend the expenditure of many millions of dollars for the installation of elaborate systems of ventilation involving the cost of maintaining them in operation when the heating plants are not going, as desirable as they may be, for the actual benefit derived.

The examination of all the 600 schools in New York was obviously out of the question, so under the advice of Mr. Armstrong, we selected 32 typical examples, ranging from modern and well managed fan-ventilated schools to older buildings in congested tenement districts, ventilated without fans, and including buildings of various sizes from one of the largest high schools to a four-room country school in Richmond Borough.

Ten of these schools were studied intensively, being visited once a week between December 2, I912 and February 14, 1913, while the other twenty-two were visited on one or more occasions between February $\Upsilon_{4}$ and March 15, rgr3. The latter group included some night schools.

The work was organized under three major heads, viz.:

I. A study of the physical and chemical condition of the air.

II. A study of the air distribution within rooms.

III. A physiological study of "crowd poison."

I. Physical and Chemical Condition of the Air-Those factors known to possess more or less physiological significance only were considered. They were (a) Temperature, (b) Relative Humidity, (c) Carbon Dioxide, (d) Dust, and (e) Bacteria.

(a) Temperature-Over 1800 determinations were made, besides some 340 daily thermograph records obtained with I 2 Tycos instruments located for various lengths of time, in different schools. The general results obtained by the sling psychrometer are shown in Fig. I. The thermograph records will be referred to under "operation."

The data are expressed in the form of distribution curves, the abscissae representing the observed values in each case and the ordinates the percentage of all observations falling within the limits of values indicated below. It is evident that these records as a whole indicate very good conditions. The temperature curve centers closely, as it should, about $+68^{\circ} \mathrm{F}$. On the whole, this result must be considered highly creditable and an 
indication that the children of the New York schools for the most part enjoy good atmospheric conditions, free from objectionable overheating. An examination of particular schools, however, shows that this general curve covers up markedly different conditions in individual cases.

(b) Relative humidity was recorded with over I 800 observations made with the standard United States Weather Bureau sling psychrometer, swung through an angle of $180^{\circ}$.

The general distribution of results in regard to relative humidity is shown in the fourth curve of Fig. I.

\section{WIDE HUMIDITY RANGE}

The range of relative humidity is seen to be a wide one. Sixty per cent of all observations, however, fall between 20 per cent and 40 per cent of saturation and the general average for all schools is 35 per cent, indicating a distinctly dry atmosphere.

We found a close correlation between outdoor temperature and indoor temperature and indoor relative humidity, closer if anything in the naturally-ventilated than in the artificiallyventilated schools. This is an important point, in view of the criticism of ten leveled at the supposedly abnormal air of the fanventilated schools. It does not make the least difference whether air is heated in the ducts or in the rooms, the same rise in temperature produces the same drying effect.

The only way to avoid dry air in the schoolroom with certainty is by means of fan ventilation, combined with artificial humidification.

(c) Carbon dioxide was determined (nearly 800 determinations) with an improved Petterson-Palmquist portable apparatus. It is recognized that a knowledge of the $\mathrm{CO}_{2}$ content of the air is of comparatively little value beyond measuring the rate of exchange, but we secured valuable data especially in connection with the night schools.

Our results in regard to carbon dioxide are summarized in the lowest graph of Fig. I.

The general average value for all schools was 9.I parts per 10,000. Sixty-six per cent of the observations fell below 8.5 parts, which may be considered a very satisfactory result on any standard. Twenty-nine per cent of the tests showed between 8.5 and I 2.5 parts, which would have been considered high on the older standards established when carbon dioxide was held to be a measure of some mysterious poisonous matter in the air.

There remain 6 per cent of the tests, however, showing over I2.5 parts which are clearly excessive. These were associated with overcrowding and deficient air supply in individual rooms.

Supplementary observations made in four schools during evening sessions (when there is no artificial ventilation) showed some very high carbon dioxide values ranging, in one case with gas burning, up to 26 .o parts.

This is a special problem which deserves more attention than it receives in many cities.

(d) Dust Particles-Nearly 700 samples were collected by filtration through sugar with an apparatus for measuring volume by time, especially devised for us by Wallace \& Tiernan (described on p. 238). After the sugar was dissolved, the dust particles were examined in an aliquot part under the microscope $(2 / 3$ in. objective), general character noted, and counted (the standard method).

The general distribution of dust counts is shown in the second graph of Fig. I. The largest number of samples showed between 200,000 and 400,000 particles per cubic foot. The general average for all schools was 601,000 particles and 20 per cent of the samples showed 800,000 or more, with a few values ranging up to $2,000,000$ and over.

The sanitary significance of these results is probably not great. Dust particles constitute a serious menace to health in industrial establishments, grinding shops, granite cutting sheds and the like, since the hard metallic or mineral particles which are found under such conditions injure the lung tissue and often form a controlling cause in the development of industrial tuberculosis. There is no evidence, however, to show that such particles as occur in ordinary schoolroom air have any such significance. The particles which we found were for the most part minute and chiefly organic in nature. In the counting cell they separated into two layers, the greater number, floating on the surface, being barely visible under the microscope and consisting in large part of mold spores; while less numerous particles settling on the bottom included larger shreds of vegetable fiber and inorganic matter.

(e) Bacteria-About 700 samples were collected by filtration through sterile sand. The sand was washed with sterile water and the bacteria plated on litmus lactose-agar, the general method recommended by the Committee of the Laboratory Section of the American Public Health Association on Standard Methods for the Examination of Air. The term "bacteria" included yeast and molds as well; all microbes, in fact, which will form visible colonies on litmus-lactose agar in five days at room temperature. The most frequent result was 25 microbes or less per cubic foot, but the high results pulled the general average up to 96 . However, 68 per cent of the samples showed counts of 100 or less and only 9 per cent over 200 .

These counts include all sorts of organisms from all sorts of sources, which are able to withstand drying long enough to be lifted up and blown about in the air. Most of them, of course, are of no sanitary significance, and the values, averaging under IOO per cubic foot and in most samples much less, must be considered satisfactory by comparison with the results reported by Miquel ( 50 bacteria per cubic foot in the air of Paris), by Tenon (40-60 bacteria per cubic foot in quiet hospital air), by Hesse ( 60 bacteria per cubic foot in a classroom before the students arrived, raised to 430 during the hour, and 1,000 just after the class had left), and by Soper ( 140 bacteria per cubic foot at the remote end of the Fulton Street Subway station, New York City).

\section{BACTERIA OF HUMAN ORIGIN}

In order to obtain an estimate of the bacteria of human origin which might at times include pathogenic forms, we made all our plates on litmus lactose-agar, as noted above, and isolated all red colonies which appeared on the plates.

It is well established that acid-forming streptococci are among the most abundant forms in the human mouth, while they are absent from sources which have not recently been exposed to human or animal pollution. We have found the number of these organisms in preliminary experimenis one and a half years ago to be quite small. We then found among 30,000 colonies isolated from 750 plates, exposed in schools with window ventila. tion, only ten mouth streptococci.

In the present study, in the examination of a total of 868 cu. ft. of air, we found 260 mouth streptococci, or thirty for every $100 \mathrm{cu}$. ft. of air. The average number of mouth streptococci for the individual schools ranged for the most part between ten and thirty-five per $100 \mathrm{cu}$. ft. In one crowded school in a poor district it rose to 75 per $100 \mathrm{cu}$. ft., and in a school in a good semi-suburban district, no streptococci were found in $4 \mathrm{I} \mathrm{cu}$. ft. of air. The general average of thirty mouth streptococci per roo ctu. ft. gives a ratio of about one of these forms to 300 total bacteria.

A child breathes less than roo cu. $\mathrm{ft}$. of air during an average school period and these mouth streptococci must, of course, be far more abundant than pathogenic forms. At a rate of twenty to twenty-five mouth streptococei per day the chance of ingesting pathogenic bacteria from the air is seen to be a slender one.

II. A Study of the Air Distribution within Rooms-This involved some 500 anemometer readings, some 2000 temperature determinations in various parts of the many schoolrooms 


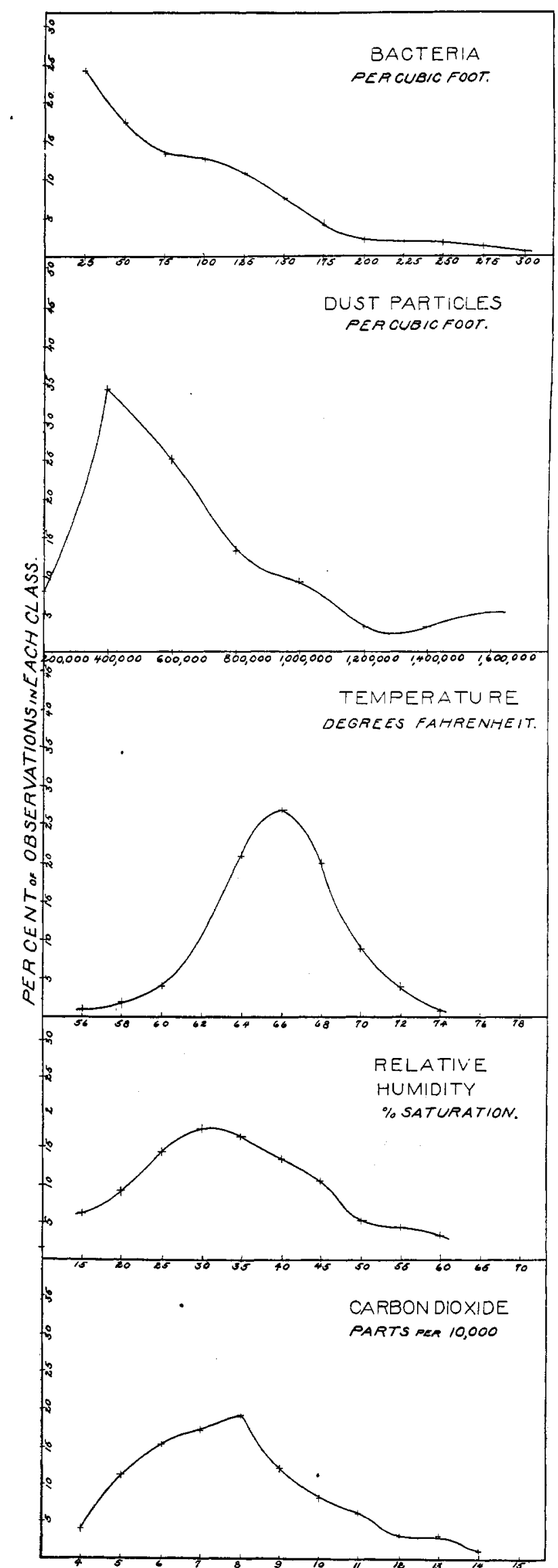

Fig. I-General Distribution of Results for ali Schools Studied

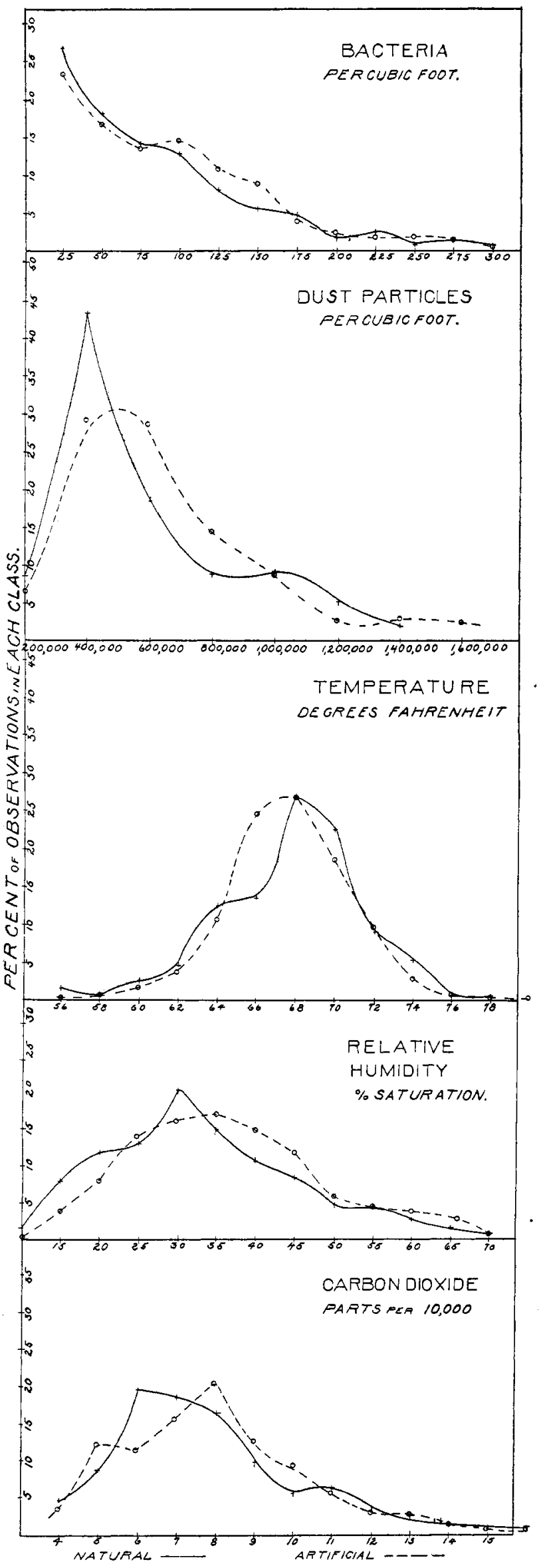

Fig. II-Distribution of Results IN Ventilated Schools 
studied. The data obtained gave some interesting facts as to how the mechanics of ventilation work out in practice.

Inlet and outlet velocities were studied with the anemometer in 50 rooms, 25 in one of the best fan-ventilated schools ( 33 Bronx), I6 in four fan-ventilated schools where high carbon dioxide values had been found and $g$ in four schools ventilated without fans. The amount of air supply in the fan-ventilated schools showed that in School 33 the amount was more than ample, while in the poorer school it was inadequate. For the most part we found a good plenum condition in all the fanventilated rooms. The very high ratios were usually in rooms with doors or windows open.

The results obtained in the naturally-ventilated rooms are not very significant, since doors and windows were freely opened. It is of interest to note, however, that in one school we found inlet velocities of 200 and 300 lin. ft. per minute without fans, maintained by unusually high temperatures of inlet air.

The circulation of air within the rooms themselves we studied by the use of smoking joss sticks and by an elaborate series of local temperature measurements. The results obtained by the use of the joss sticks in about 70 rooms were very hard to correlate. In about half of the fan-ventilated rooms there were clean-cut currents which could be traced across the upper part of the room, down the side wall opposite and back along the floor to the outlet. In an equal number of cases, however, the currents were indefinite and broken and in a few cases no currents at all could be discerned. In the rooms without fans the currents were usually very erratic, although in one or two cases a definite circulation was produced by windows open at top and bottom. In general the naturally ventilated rooms were much more subject to local drafts than were those ventilated by fans.

The local temperature observations were on the whole more valuable as throwing light on air circulation. In 24 rooms in fan-ventilated schools we found an average increase in temperature between inlet and outlet of $4.3^{\circ} \mathrm{F}$.

The ou let temperature corresponds very closely to the general room average. This indicates that the outgoing air is a pretty fair sample of that in the room and that its temperature may be taken as a fair measure of that of the room as a whole.

The difference between bottom ( $3 \mathrm{ft}$. above floor) temperature and top ( $12 \mathrm{ft}$. above floor) temperatures was inconsiderable, and more variable than might have been expected. Of twentysix rooms in which both were determined, just half showed a higher temperature at the top than at the bottom, while in the rest the upper air was cooler. The top excesses were bigher than the bottom excesses, however, averaging over $2.0^{\circ}$ instead of under $1.0^{\circ}$.

The slight extent of the differences observed is probably due to the fact that, on the one hand, cool air was being blown in at the top of the room while, on the other hand, the air, as it was warmed in the room, tended naturally to rise. This condition must interfere to some extent with normal air circulation and offers a certain argument in favor of upward as opposed to the usual downward ventilation.

Finally, the range between the maximum and minimum individual temperatures observed in the room is significant as a measure of general air circulation. The differences ranged for individual rooms between $I .7^{\circ}$ and $I 2.0^{\circ}$, and averaged $5.8^{\circ}$, showing on the whole a fairly good mixture of the air. These observations were all made in fan-ventilated rooms.

In rooms ventilated without fans, conditions were more variable. Among eighteen rooms without fan-ventilation (that is, without a current of cool air blown in near the top) all but one showed a higher ceiling temperature, the excess in two cases being over I I. $0^{\circ}$, and averaging $5.8^{\circ}$.

Another marked difference between the fan-ventilated and the artificially-ventilated rooms lies in the evenness of temperatures at different points. The range of difference between maximum and minimum room temperatures for the fan-ventilated rooms as noted above, was from $\mathrm{I} .7^{\circ}$ to $\mathrm{I} 2.0^{\circ}$, and the average $5.8^{\circ}$ For thirty-eight naturally-ventilated rooms, it ranged from I. $2^{\circ}$ to $20.2^{\circ}$, and averaged $7.9^{\circ}$. Obviously, the air circulation is rather defective when such conditions exist.

It may be of interest to note that in five of the naturallyventilated rooms, all in one building, the temperature of the incoming air was respectively, $83^{\circ}, 86^{\circ}, 90^{\circ}, 98^{\circ}$, and $125^{\circ} \mathrm{F}$. In the latter case one of our thermometers (registering to $130^{\circ}$ ) was burst by the heat of the inlet air the first time the temperature was taken.

\section{COMPARISON OF NATURALIY- AND ARTIFICIALLY-VENTILATED SCHOOLS}

For the purpose of estimating the value of fan-ventilation, as actually operated in New York schools, curves were plotted for all the schools classified on this basis and this curve is reproduced in Fig. II. Of course, it must be understood that by natural ventilation is meant simply that fans were not running. In almost all cases there were ducts and of ten heating coils were within them and air was undoubtedly passing through them. So, on the other hand, where fans were in operation, windows were often open and outside air passing in or out through them. The distinction is made solely on the fact that fans were or were not in operation in connection with the particular room in which each test was made.

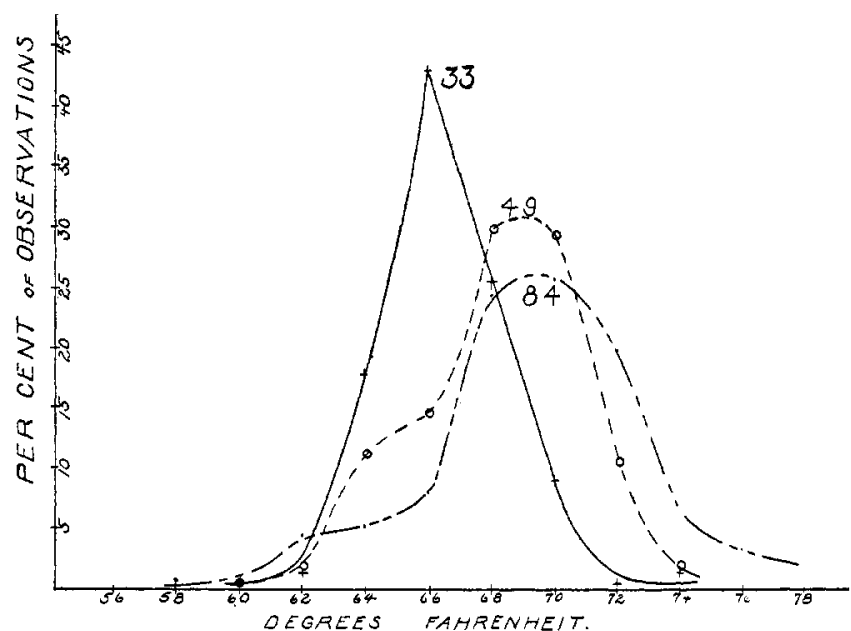

Fig. III-ThMPeratere CUrves, Public Schoor,s Nos, 33, 49, 84 33-Good Fan Ventilation 49-Naturally-Ventilated 84-Badly Operated Fan Ventilation

The general results for the two classes of schools are on the whole remarkably alike. The fan-ventilated schools show more dust, more humidity more carbon dioxide and a somewhat more equable temperature; but none of the differences is very great or very significant.

In dust and carbon dioxide, the fan-ventilated schools appear slightly inferior to the others. In humidity they are better (if dry air be a disadvantage). In temperature they are also somewhat better, showing less observations over $72^{\circ}$.

So far as temperature is concerned, however, it should be noted that the curve for the fan-ventilated class conceals wide variations between the individual schools included in it. Of our ten schools more thoroughly studied, it is noteworthy that the four really good records (from the standpoint of temperature) were in fan-ventilated schools. The three wholly or partly naturallyventilated schools are mediocre or poor; and two fan-ventilated schools are worst of all.

In Fig. III are shown typical curves for these three classes. Either almost perfect conditions or very poor conditions may be obtained with fan-ventilation according to the care and intelligence of the janitor in charge. 


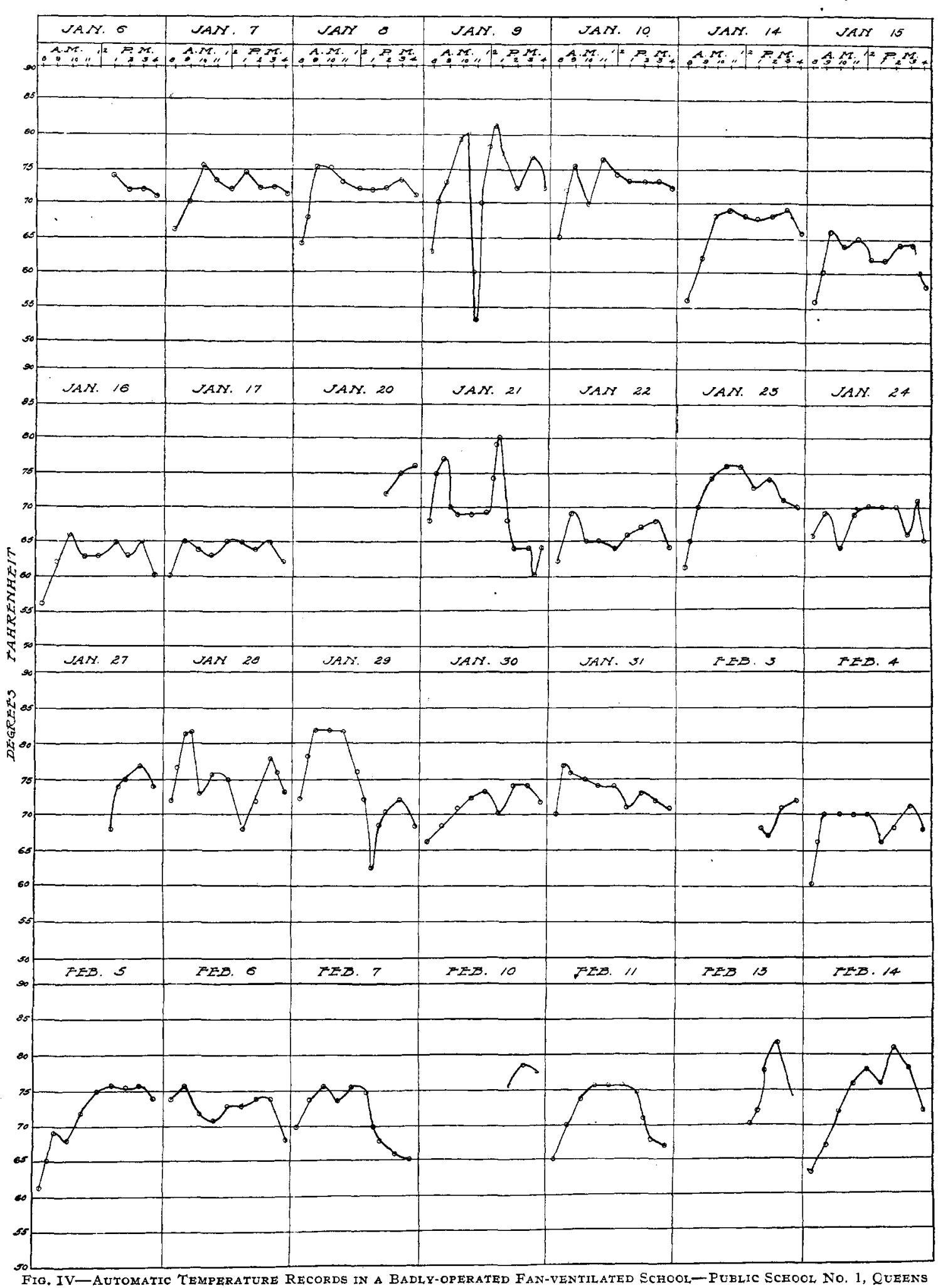

On the whole it can be said that, comparing the actual condition of rooms ventilated with and without fans, New York was not deriving any material advantage from its fan-ventilation last winter as actually operated.

\section{THE OPERATION OF A VENTILATION SYSTEM}

A system of ventilation inherently not the best may give good results by good operation, and an excellent system may give poor results by poor or unintelligent operation. This folliful statement was vividly illustrated in our investigation. We found certain schools of either type which had an ample air supply and uniformly low carbon dioxide values. . We found other schools, of both types, in which the supply of air was inadequate and carbon dioxide figures consequently high. In the case of fan-ventilated schools this usually meant low inlet velocities (sometimes inadequate inlet areas) or overcrowding, while in the naturally-ventilated schools it meant either overcrowding or neglect to open windows. 
The most striking results of careless operation were shown, however, in the matter of overheating. In the case of the naturally-ventilated schools the coöperation of both janitors and teachers is required in order to secure good results, and, where so many persons are concerned, it is practically impossible to reach a maximum of efficiency. Such results as that indicated in Fig. III for School 33 could scarcely be attained where window ventilation plays any large part.

In fan-ventilated schools, on the other hand, the whole responsibility rests (or should rest) with the janitor, and either very good or very bad results may be attained, according to his intelligence and responsibility. The continuous records obtained by our recording thermographs brought out the importance of the operating factor with starlling clearness, and four of our curves are reproduced herewith to illustrate the variation which occurred (Figs. IV and V).

In order to remedy this condition we urged that a thermograph of some improved type be installed in each school building pounds of human origin can be detected in respired air by the delicate physiological reaction of anaphylaxis, we devoted considerable attention to this point. Dr. D. R. Lucas, who conducted this part of the investigation, was able to demonstrate easily the presence of such specific proteid substances in the saliva under carefully controlled conditions, but was unable to detect them in material condensed from the breath or in air heavily contaminated by the respiration and exhalation of dogs and human beings. We were forced to conclude that "there is at present considerable uncertainty as to the presence of such specific proteid substances in demonstrable amounts in respired air and that there is absolutely no evidence of the presence of any organic substances of a deleterious nature in such air."

Similar experiments carried out simultaneously and independently by Dr. Charles Weisman at Columbia University and published as a Doctor's Dissertation have led to the even more definite conclusion that "the results of these experiments disprove the statements of Rosenat and Amoss that the breath

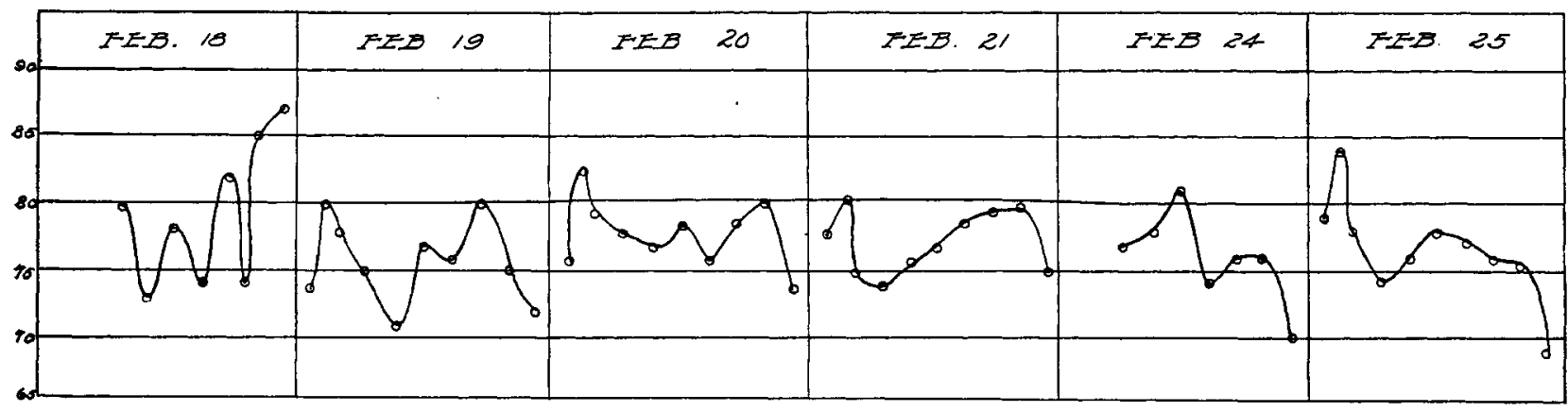

Fig. V-Automatic Temperature Records in a Badly-operated Naturally-ventilated School-Puhlic School No. 25, Manhattan

and that the records obtained be carefully inspected and made the basis for an efficient control of ventilating systems and janitorial service and we recommended that these records be supplemented by periodical studies of temperature and volume of air at the room inlets.

\section{CRITERIA FOR SCHOOL-ROOM AIR}

The chief value of these investigations lies perhaps in their possible use as a basis for comparative studies in the schools of other cities, which are greatly needed, if scientific records are to take the place of opinion in the field of school ventilation.

The results obtained in regard to dust and bacteria seem to indicate that, so far as these suspended matters are concerned, the air of the New York schools is in a satisfactory condition, without any special measures of protection, provided we regard the air of New York as good. Personally, I know the air in New York City is better than in some cities, it is also worse than in some other cities. The topographic conditions are an imporlant factor. The general air conditions can and should be improved, for example by more extended washing down of the streets. I have not ceased in my hopes furthermore to see the city wash down its streets at suitable intervals with proper disinfecting solutions.

So far as carbon dioxide is concerned, our results indicate that it is comparatively easy, either with or without the use of fans, to keep the air in a schoolroom so changed that its carbon dioxide will average well under Io parts per Io,00o and will rarely exceed I 2 parts. This test furnishes an excellent measure of air change and under ordinary conditions such an air change is essential in order to remove odors and preserve a freshness agreeable to the senses. Where air is recirculated, however, with washing or chemical treatment to remove odors, the carbon dioxide standard may have to be relaxed still further, although it will always be of value as an index of what is going on in the way of air dilution.

III. A Physiological Study of "Crowd Poison"-In view of the claim of Rosenau and Amoss that specific proteid com- contains 'volatile' protein and that such 'volatile' protein is an important respiratory factor."

While subsequent investigations may prove it different, at present we may agree, in large part at least, with the conclusion reached by Flügge eight years ago, viz., "Whenever in closed, crowded rooms certain impairment of health ensues, such as headache, dizziness, nausea, etc., these symptoms are to be attributed solely to heat retention."

Overheating seems to be the chief evil to be guarded against in school ventilation at present. Associated with this is regulated humidification.

COlLege of the City of New York

\section{THE NEW YORK STATE COMMISSION ON VENTILA- TION AND ITS PROBLEMS}

By C.-E. A. WinsLow ${ }^{1}$

Rudolph Hering has well said, in his recent address as President of the American Public Health Association, that the subject "of supplying suitable air to enclosed spaces, of heating, ventilating and removing foul air, is one which as yet is not sufficiently well understood in detail, and on which there are still opposing opinions. In fact, of all of the branches of sanitary engineering at the present time it needs most investigation and most study." In the last few years, however, a new and encouraging interest has been manifested in the study of ventilation problems. Among the various signs of this awakening none is perhaps more significant than the creation of the New York State Commission on Ventilation to undertake a broad and fundamental study of the physiological and mechanical problems which underlie the art of air conditioning. For the first time, in this country, at least, a sum of money is to be applied toward the solution of these problems which, though small in comparison with the magnitude of the task, is large enough to give

1 Chairman, New York State Commission on Ventilation. 